OPEN ACCESS

Edited by:

Zhiyong Gao,

Central South University, China

Reviewed by:

Yin Wanzhong

Northeastern University, China

Haiyun Xie,

Kunming University of Science and

Technology, China

*Correspondence:

Caibin Wu

caibin.wu@jxust.edu.cn

Specialty section:

This article was submitted to

Colloidal Materials and Interfaces,

a section of the journal

Frontiers in Materials

Received: 23 October 2019 Accepted: 13 May 2020

Published: 17 June 2020

Citation:

Liao N, Wu C, XU J, Feng B, Wu J and

Gong Y (2020) Effect of Grinding

Media on Grinding-Flotation Behavior

of Chalcopyrite and Pyrite.

Front. Mater. 7:176

doi: 10.3389/fmats.2020.00176

\section{Effect of Grinding Media on Grinding-Flotation Behavior of Chalcopyrite and Pyrite}

\author{
Ningning Liao ${ }^{1}$, Caibin $W u^{1,2 *}$, Jindong $X u^{1}$, Bo Feng ${ }^{1,2}$, Ji Wu ${ }^{1}$ and Yuan Gong ${ }^{1}$ \\ ${ }^{1}$ College of Resources and Environmental Engineering, Jiangxi University of Science and Technology, Ganzhou, China, \\ 2 Jiangxi Key Laboratory of Mining Engineering, Jiangxi University of Science and Technology, Ganzhou, China
}

Grinding media have significant influence on the flotation of chalcopyrite and pyrite. This effect is mainly related to the change in the surface properties of chalcopyrite and pyrite. This paper investigates the influence of steel ball and nano-ceramic ball grinding on the floatability of chalcopyrite and pyrite. Flotation results, as well-scanning electron microscopy (SEM), X-ray photoelectron spectroscopy (XPS), ultraviolet spectrophotometer, and zeta potential measurement results indicate that nano-ceramic ball grinding is beneficial to the flotation of chalcopyrite. Flotation results also indicate that chalcopyrite has better floatability after nano-ceramic ball grinding compared with steel ball grinding. Results of adsorption experiments show that nano-ceramic ball grinding contributes to the adsorption of isobutyl xanthate to chalcopyrite. XPS and SEM techniques demonstrated that steel ball grinding easily produces oxidation species at the surface of chalcopyrite, thereby reducing its floatability. Results from this study also confirmed that steel ball grinding is beneficial to the flotation of pyrite. Therefore, nano-ceramic media grinding produces better selective flotation in chalcopyrite than steel media grinding.

Keywords: chalcopyrite, pyrite, nano-ceramic ball, steel ball, grinding, flotation

\section{INTRODUCTION}

Grinding operation is an essential process in a mineral processing plant. The primary purpose of grinding is to achieve monomer dissociation between useful minerals, gangue minerals, and other minerals. Grinding also provides the right-sized raw materials for the downstream sorting process. The grinding process is affected by different factors, such as ore characteristics, grinding media, and grinding concentration. Moreover, grinding media have important effect on subsequent flotation operations by changing the grinding pulp environment (Martin et al., 1991; Palm et al., 2010, 2011; Li and Gao, 2017, 2018; Corin et al., 2018; Feng et al., 2019), particularly the pulp chemistry and surface properties of minerals in the flotation. The effect of the grinding media on flotation is mostly determined using three parameters, namely dissolved oxygen concentration, slurry potential, and galvanic interaction between the medium and the mineral (Erdemoglu and Sarikaya, 2002; Gonçalves et al., 2003; Peng and Grano, 2010a,b). The electrochemical standard potentials interaction between sulfide minerals and grinding media during the grinding processing. The grinding media act as the anode, whereas the mineral acts as the cathode (Gonçalves et al., 2003). Steel media generate hydrophilic products on mineral surfaces, reduce the natural floatability of minerals, and also affect the adsorption of collectors at the surface of mineral (Heyes and Trahar, 1979; Greet et al., 2004; Huang and Grano, 2006; Bruckard et al., 2011; Feng et al., 2020). 
Studies have shown that the grinding media can affect the flotation of chalcopyrite and pyrite. Galvanic interaction between the steel media and chalcopyrite forms iron hydroxide species at the surface of the chalcopyrite, which affects the adsorption of collectors and reduces the floatability of the chalcopyrite (Forssberg et al., 1988; Rao and Natarajan, 1988). However, it has been reported that mild steel grinding is beneficial to the flotation of pyrite (Learmont and Iwasaki, 1984). A possible explanation is that the collector produced dixanthogen at the surface of the pyrite (Woods, 1976). Another reason is that galvanic interaction between the iron medium and the mineral surface generated elemental sulfur at the surface of the pyrite (Rao et al., 1976). Yuan et al. (1996) and Van Deventer et al. (1991) found that chalcopyrite separation from pyrite has no advantage in strong oxidizing stainless media grinding environment but was restored in a mild steel medium reducing environment. Peng et al. (2003a) and Peng et al. (2003b) found that chalcopyrite separation from pyrite in a chromium medium grinding environment is better than in a mild steel medium. Stainless media or inert media (ceramic media, SAG pebble) are more beneficial to chalcopyrite flotation. Inert medium grinding can improve the pulp environment and flotation recovery of chalcopyrite (Forssberg et al., 1988; Ahn and Gebhardt, 1991; Martin et al., 1991; Guo et al., 2019). As compared with steel balls used as grinding media, SAG pebble is beneficial to improve the recovery rate of copper ore (Shi and Zhou, 2019; Wu et al., 2019). The flotation performance of calcite after ceramic ball grinding is better than that that of steel ball grinding (Yao

TABLE 1 | Chemical analysis results of chalcopyrite and pyrite.

\begin{tabular}{lcc}
\hline Element & \multicolumn{2}{c}{ Composition (\%) } \\
\cline { 2 - 3 } & Chalcopyrite & Pyrite \\
\hline $\mathrm{Cu}$ & 31.86 & 0.00 \\
$\mathrm{Fe}$ & 27.35 & 44.01 \\
$\mathrm{~S}$ & 32.31 & 54.62
\end{tabular}

et al., 2019). Zhang et al. have also compared the flotation kinetics of pyrite with nano-ceramic balls and cast iron balls (Zhang et al., 2019). Nano-ceramic balls, which were invented and patented by Jingdezhen Betterwear New Material Co, Ltd, Jiangxi Province, China (Zhang et al., 2013). Nano-ceramic balls were made of nano-scale alumina powder and other minerals. In our past research, nano-ceramic balls as a fine grinding media can improve the grade and recovery of copper concentrate of copper sulfur ore and have achieved good industrial applications in Yinshan Mining Concentrator of Jiangxi Copper Corporation, China. Nano-ceramic balls as new grinding media have light density, good wear resistance, no iron pollution of pulp and other characteristics (Liao et al., 2019).

However, the surface of ground chalcopyrite, pyrite and the flotation products, as well as the effect of the medium on adsorption of collectors to minerals have not been clearly clarified in nano-ceramic grinding media. This study investigated the effects of nano-ceramic ball and steel ball grinding on chalcopyrite and pyrite flotation behavior, as well as the effects on the surface morphology of the ground products and flotation concentrate. Adsorption between the collector and the mineral was analyzed using adsorption tests in two grinding media.

\section{MATERIALS AND METHODS}

\section{Materials and Reagents}

The purities of chalcopyrite and pyrite are above 90\% (Table 1). The X-ray diffraction (XRD) analysis of chalcopyrite and pyrite is shown in Figure 1. The grinding medium of this experiment used $15 \mathrm{~mm}$ nano ceramic balls $\left(95 \% \mathrm{Al}_{2} \mathrm{O}_{3}\right)$ and $12 \mathrm{~mm}$ steel balls $(3 \% \mathrm{C})$ of equal quality. The nano-ceramic balls were sourced from Jingdezhen Betterwear New Material Co. Ltd., China, whereas the steel balls were from Goldpro New Material Co. Ltd., China. Grinding media with chemical compositions, densities were selected for the tests as shown in Table 2.

The collector used in this study was isobutyl xanthate obtained from Shanxi Baoji Chemical Reagent Factory. Pine oil was used as a frother in flotation. Analytical grade sodium hydroxide and
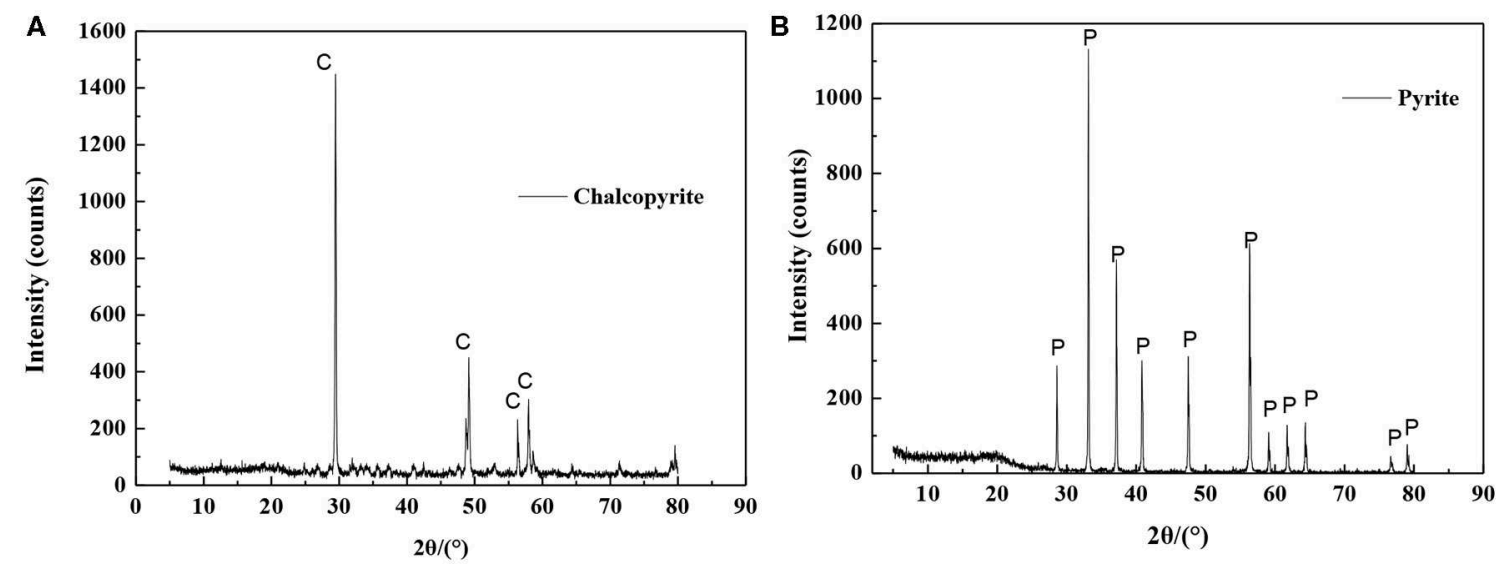

FIGURE 1 | XRD patterns of (A) chalcopyrite and (B) pyrite. 
TABLE 2 | Grinding media, chemical compositions, densities.

\begin{tabular}{lccc}
\hline Media type & \multicolumn{2}{c}{ Chemistry (wt. \%) } & Density $\left(\mathbf{g} / \mathbf{c m}^{\mathbf{3}}\right)$ \\
\cline { 2 - 3 } & $\mathbf{A l}_{\mathbf{2}} \mathbf{O}_{\mathbf{3}}$ & $\mathbf{C}$ & \\
\hline Steel ball & 0.00 & 3.00 & 7.80 \\
Nano- ceramic ball & 95.00 & 0.00 & 3.70 \\
\hline
\end{tabular}

hydrochloric acid were used as $\mathrm{pH}$ adjusters, which were supplied by Xilong Scientific Co. Ltd., China.

\section{Experimental Methods} Grinding Tests

The chalcopyrite and pyrite are crushed with a small hammer to $1-2 \mathrm{~mm}$, then, the samples were ground in a grinding bowl using the $15 \mathrm{~mm}$ nano-ceramic balls and $12 \mathrm{~mm}$ steel balls (of the same weight) as grinding media. Firstly, the grinding medium and appropriate amount of sample were added in the grinding bowl. Secondly, the samples were ground with a grinding rod for $3 \mathrm{~min}$. Then, the grinding medium were removed from the grinding bowl and the samples were sieved using 200 mesh and 400 mesh sieves. Finally, upper 200 mesh samples were return to regrind until all samples were reached passing 200 meshes. Samples with particles size of $0.038 \sim 0.075 \mathrm{~mm}$ were used for the flotation test, whereas samples with particle size of the passing $0.038 \mathrm{~mm}$ were used for the adsorption test. The surface morphology of the passing $0.038 \mathrm{~mm}$ ground samples were analyzed using an MIA650F scanning electron microscope (American FEI Company).

\section{Micro-Flotation Tests}

The flotation test was conducted in a $40 \mathrm{ml}$ XFG flotation machine. The flotation machine rotational speed of the impeller was $1,992 \mathrm{r} / \mathrm{min}$, and each flotation used $2 \mathrm{~g}$ of the samples. We added $2 \mathrm{~g}$ of the samples and distilled water into a $50 \mathrm{ml}$ beaker. The suspended minerals were placed in an ultrasonic bath for $5 \mathrm{~min}$. Then, the mineral added to the flotation cell was conditioned for $3 \mathrm{~min}$ and adjusted to the desired $\mathrm{pH}$ value with $\mathrm{HCl}$ or $\mathrm{NaOH}$ solutions. Isobutyl xanthate and pine oil were sequentially added into the flotation cell at a conditioning time of 3 and $1 \mathrm{~min}$, respectively. The flotation concentrate was filtered and dried, and the flotation recovery rate was calculated using the mass ratios of floated and un-floated fractions. The surface morphology of the flotation concentrate product was analyzed using an MIA650F scanning electron microscope (SEM).

\section{Adsorption Tests}

The amount of adsorption at the surface of mineral was determined using the residual concentration method. The specific surface areas of pyrite and chalcopyrite were obtained using the BET test. The adsorption tests were conducted using an ultraviolet spectrophotometer. We placed $2.0 \mathrm{~g}$ of the passing $0.038 \mathrm{~mm}$ samples into a $40 \mathrm{~mL}$ conical flask, and adjusted the suspension to the desired $\mathrm{pH}$ value of 8 with dilute $\mathrm{NaOH}$ or $\mathrm{HCl}$ solutions. A given concentration of isobutyl xanthate mixed with distilled water was added into a $40 \mathrm{ml}$ solution. After dispersion in a high-speed centrifuge for $15 \mathrm{~min}$ at a rotation speed of 1,500 $\mathrm{r} / \mathrm{min}$, the supernatant was filtered for measurement using an ultraviolet spectrophotometer. The amount of isobutyl xanthate adsorbed at the surface of chalcopyrite and pyrite was calculated as given in Equation 1 (Qu et al., 2016):

$$
\mathrm{Q}_{\mathrm{t}}=\frac{\mathrm{V} \cdot \mathrm{C}_{\mathrm{s}}}{\mathrm{MS}}
$$

where $Q_{t}$ is the amount of adsorption of isobutyl xanthate to the surfaces of chalcopyrite or pyrite surfaces at time $\mathrm{t}\left(\mathrm{mol} \cdot \mathrm{m}^{-2}\right), \mathrm{C}_{\mathrm{s}}$ is the adsorption concentration of isobutyl xanthate $\left(\mathrm{mol} \cdot \mathrm{L}^{-1}\right), \mathrm{V}$ is the volume $(\mathrm{L}), \mathrm{S}$ is the specific surface area of chalcopyrite or pyrite $\left(\mathrm{m}^{2} \cdot \mathrm{g}^{-1}\right)$, and $\mathrm{M}$ is the mass of chalcopyrite or pyrite $(\mathrm{g})$.

\section{X-ray Photoelectron Spectroscopy (XPS)}

The concentration of surface species on the flotation concentrates was determined using a Thermo Scientific ESCALAB 250Xi XPS instrument (USA). This instrument used the focused beam of monochromatic $\mathrm{Al} \mathrm{K} \alpha \mathrm{X}$-rays $(1486.68 \mathrm{eV})$ operating at $140 \mathrm{~W}$. Firstly, the survey mode was used to obtain the elements on the surfaces of flotation concentrates. Then, the high-resolution mode was used to observe the chemical bonds and oxidation states of $\mathrm{Fe}$ and $\mathrm{S}$. The spectral data were processed using Avantage XPS and Origin software. Details of this procedure have been reported previously by Beke et al. (2009) and Rabieh et al. (2017).

\section{Zeta Potential Measurement}

The zeta potential was measured using an A80030E Zeta Probe. The mineral samples were added to distilled water to form a $0.5 \%$ mineral solution. After stirring for $5 \mathrm{~min}$, the zeta potential of the solution was tested at a given $\mathrm{pH}$ in the presence and absence of isobutyl xanthate at a concentration of $1 \cdot 10^{-4} \mathrm{~mol} \cdot \mathrm{L}^{-1}$.

\section{Results and Discussion Effect of Different Grinding Media on Grinding Performance}

Figure 2 shows the SEM images of chalcopyrite and pyrite after dry grinding in mortar. As seen from Figure 2A, it appears that the surface of chalcopyrite after dry grinding using steel balls is rough and has a structure consisting of cracks. Figure 2B shows the smooth surface of chalcopyrite after dry grinding using nano-ceramic balls which has little cracks on. Figures 2C,D indicated that the surface morphology of pyrite is rough after ground with nano-ceramic balls or steel balls. The surface of the pyrite after ground with steel ball (Figure 2C) has more fine particles attached to the large particles than the surface after ground with nano-ceramic ball (Figure 2D). There are less crack on the surface of the pyrite after grinding with nano-ceramic balls as shown in (Figure 2D) in comparison with steel balls (Figure 2C). Hence, in the case of dry grinding, the effect of the grinding media on the surface morphology of the mineral is related to the type of the mineral. Moreover, the surrounding of larger particles by smaller particles and crack on the surface of mineral may be owing to the mechanical force of grinding media, 
A

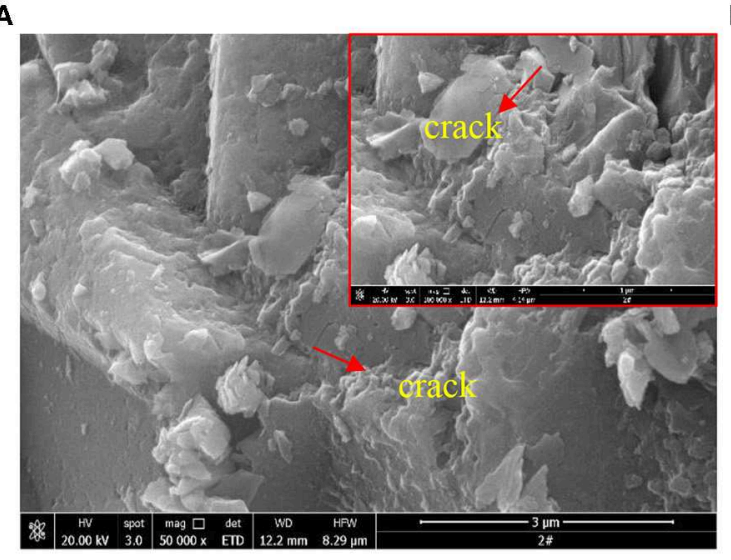

C

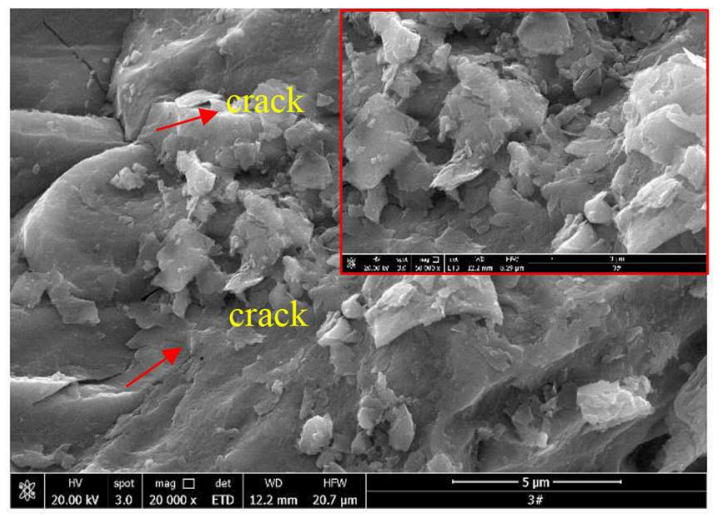

B

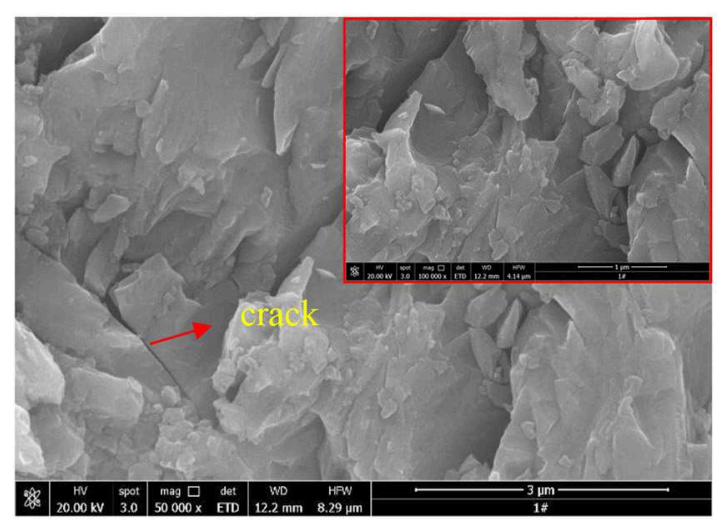

D

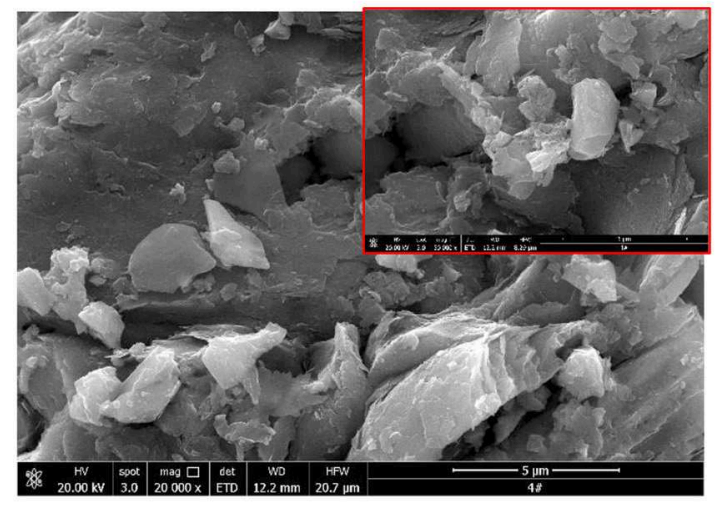

FIGURE 2 | SEM images of chalcopyrite and pyrite after dry grinding: (A) Chalcopyrite (steel ball); (B) Chalcopyrite (nano-ceramic ball); (C) Pyrite (steel ball); (D) Pyrite (nano-ceramic ball).

because the mechanical actions between the nano-ceramic balls and chalcopyrite or pyrite are small.

\section{Effect of Different Grinding Media on Flotation}

Figure 3 shows the effects of $\mathrm{pH}$ on the flotation recovery of chalcopyrite and pyrite after ground using nano-ceramic balls and steel balls. The recovery of chalcopyrite increased as the $\mathrm{pH}$ increased after ground using nano-ceramic balls and steel balls. Chalcopyrite exhibited good floatability after ground using nanoceramic balls compared with ground using steel balls. Pyrite exhibited the opposite trend as the recovery of pyrite decreased with the increase in $\mathrm{pH}$. Pyrite exhibited good floatability using steel ball grinding. This result is consistent with the result obtained in the study by Peng et al. (2003a,b).

Figure 4 shows the effects of isobutyl xanthate concentration on the flotation recovery of chalcopyrite and pyrite at $\mathrm{pH} 8.0$ after ground using nano-ceramic balls and steel balls. The flotation recoveries of chalcopyrite and pyrite increased with the increase in the isobutyl xanthate concentration. The recovery of pyrite increased sharply before the initial concentration reached $1 \cdot 10^{-4}$ $\mathrm{mol} \cdot \mathrm{L}^{-1}$ and then remained stable, whereas that of chalcopyrite increased slowly before the initial concentration reached $1 \cdot 10^{-4}$ $\mathrm{mol} \cdot \mathrm{L}^{-1}$ and then remained stable. This indicates that the

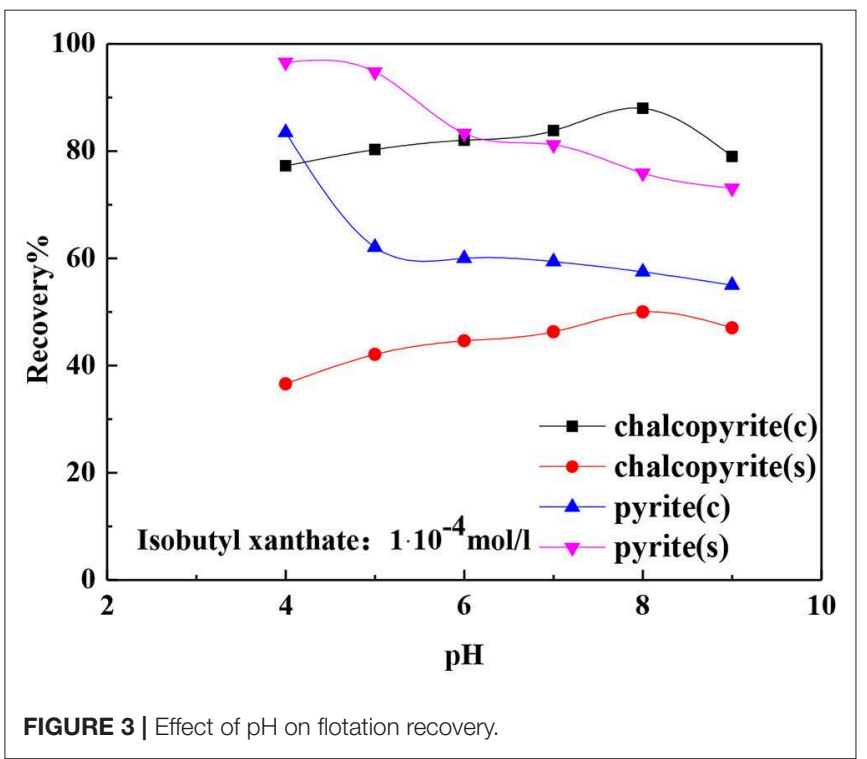

floatability of chalcopyrite in ceramic media and the floatability of pyrite in iron media are good. 
To investigate this trend, we performed scanning electron microscopy analysis of chalcopyrite and pyrite flotation concentrates at a $\mathrm{pH}$ of 8 and the addition of $1 \cdot 10^{-4} \mathrm{~mol} \cdot \mathrm{L}^{-1}$

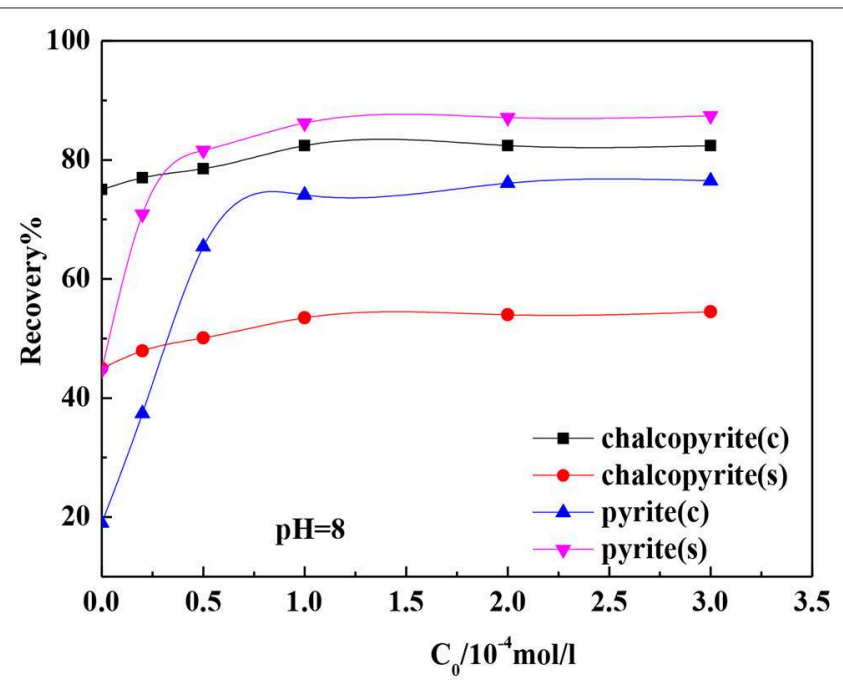

FIGURE 4 | Effect of isobutyl xanthine concentration on flotation recovery. of isobutyl xanthate concentration. Figure 5 shows SEM images of chalcopyrite and pyrite flotation concentrates. The surface of the chalcopyrite flotation concentrate ground with nano-ceramic balls is smooth, whereas there are many flocs on the surface ground with steel balls. The flotation of chalcopyrite was affected by the hydrophilic products generated at the surfaces by the steel media grinding (Heyes and Trahar, 1979; Greet et al., 2004; Yekeler et al., 2004). The surface of the pyrite flotation concentrate has more flocs on the surface ground with steel balls than ground with nano-ceramic balls. The flotation of pyrite improved after ground with steel balls owing to the galvanic interaction between the steel media and the mineral surface, which generated elemental sulfur at the surface of the pyrite (Rao et al., 1976).

\section{Effect of Different Grinding Media on Adsorption}

The adsorption of chalcopyrite, pyrite, and the collector is affected by many factors such as the $\mathrm{pH}$, the type of collector, and the grinding medium (Heyes and Trahar, 1979; Greet et al., 2004; Huang and Grano, 2006; Bagci et al., 2007; Qu et al., 2016; Huang X. et al., 2019). The adsorption of the collector to chalcopyrite is affected by the grinding medium mainly because the galvanic action of the iron medium results in adsorption of
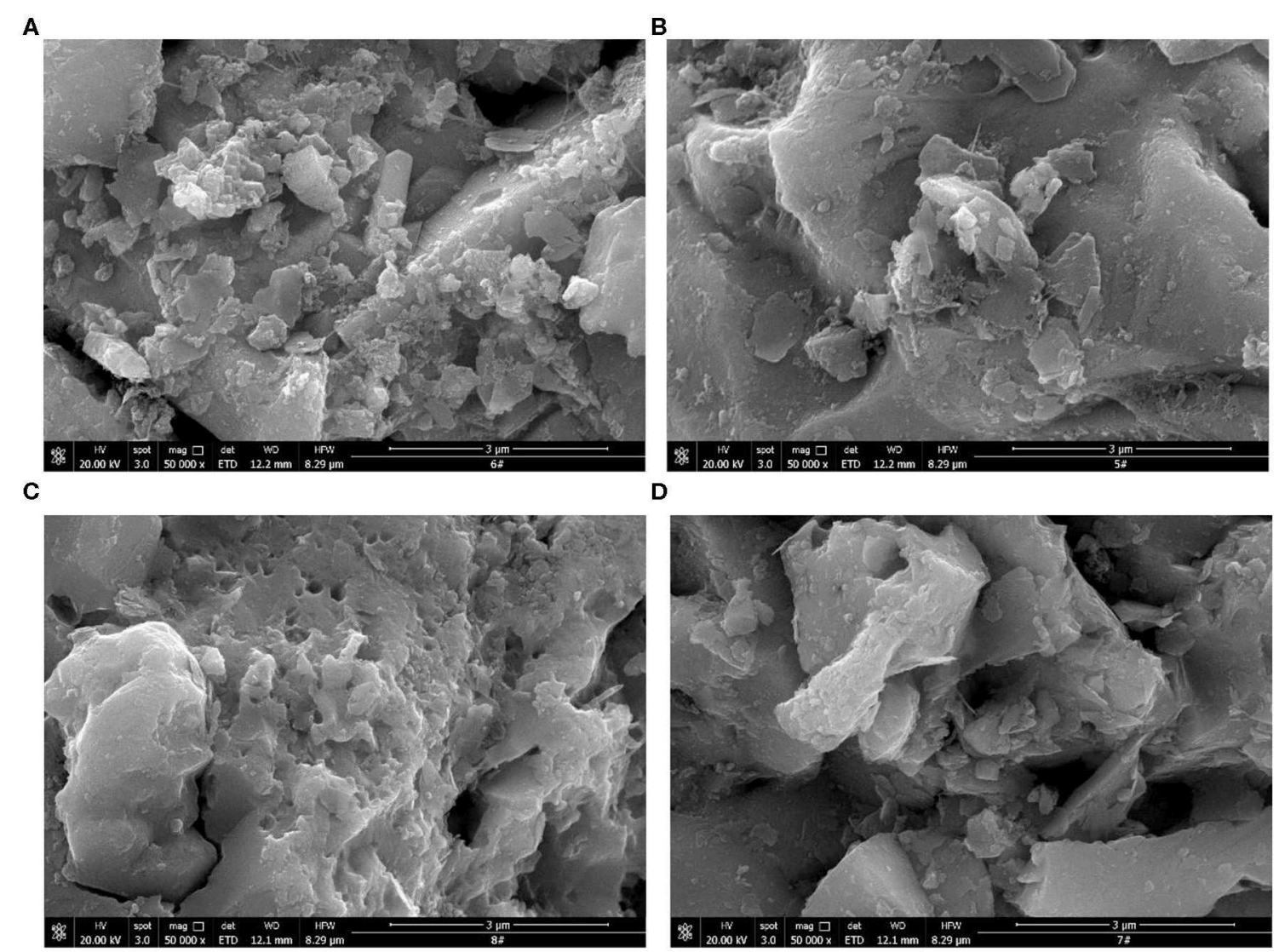

FIGURE 5 | SEM images of chalcopyrite and pyrite flotation concentrates: (A) Chalcopyrite (steel ball); (B) Chalcopyrite (nano-ceramic ball); (C) Pyrite (steel ball); (D) Pyrite (nano-ceramic ball). 
the hydroxide of the iron at the mineral surface, which affects the adsorption of the agent at the surface of mineral (Heyes and Trahar, 1979; Greet et al., 2004; Huang and Grano, 2006). Qu et al. (2016) found that HATTs(3-hexyl-4-amino-1,2,4-triazole5 -thione) exhibited strong adsorption capacity for chalcopyrite at pH 4 8. Bagci et al. (2007) found that selective and non-selective collectors can improve the amount of adsorption of the collector at the surface of chalcopyrite.

Figure 6 shows the relationship between the amount of adsorption of isobutyl xanthate at the surfaces of chalcopyrite or pyrite and the isobutyl xanthate concentration. The figure shows that with the increase in the concentration of isobutyl xanthate, the amount of adsorption at the chalcopyrite surface increases, and the amount of adsorption of isobutyl xanthate with ceramic ball grinding is larger than that of steel ball grinding. This result is consistent with the result obtained by Qu et al. (2016). The authors reported that the adsorption of the collector at the surface of mineral increases as the concentration of collector increases. Nano-ceramic balls can improve the pulp environment and contribute to the adsorption of collectors molecules at the surface of chalcopyrite, which in turn enhances the flotation of minerals (Ahn and Gebhardt, 1991; Martin et al., 1991). Pyrite exhibits the opposite trend. In iron media grinding environment, the collector produces dixanthogen at the surface of the pyrite and forms Fe-collector complexes (Woods, 1976; Nagaraj and Brinen, 2001). Therefore, the amount of adsorption of isobutyl xanthate at the surface of pyrite in iron media is higher than that of ceramic media.

Figure 7 shows the relationship between the adsorption rate and isobutyl xanthate concentration. The figure shows that with the increase in the concentration of isobutyl xanthate, the adsorption rate at the surface of chalcopyrite first increased and then stabilized, and the adsorption rate of isobutyl xanthate to chalcopyrite ground with ceramic ball grinding is higher than that of ground with steel ball grinding; pyrite exhibited the opposite trend.

\section{XPS Analysis}

The chalcopyrite and pyrite flotation concentration at $\mathrm{pH}$ of 8 and addition of $1 \cdot 10^{-4} \mathrm{mo} \cdot \mathrm{L}^{-1}$ of isobutyl xanthate concentration were also analyzed using XPS. The survey spectra of chalcopyrite and pyrite were used to determine the surface element content of the samples under different grinding media. The high-resolution spectra of $\mathrm{Fe}$ and $\mathrm{S}$ provided information about the oxidation state and chemical bonding of Fe and $\mathrm{S}$.

Figures 8A,B show the survey spectra of chalcopyrite and pyrite, respectively. The percentage of elements at the surface of the samples are presented in Table 3. Compared with chalcopyrite ground with steel balls, grinding with nano-ceramic balls decreased the iron concentration at the chalcopyrite surface from 11.02 to $10.63 \%$ and the oxygen concentration from 48.8 to $39.71 \%$, whereas the sulfur concentration increased from 8.19 to $16.38 \%$. The increase in sulfur concentration at the surface of chalcopyrite after the addition of isobutyl xanthate is due to the adsorption of isobutyl xanthate, whereas the decrease in oxygen concentration suggests the removal of surface oxidation species from the surface of chalcopyrite (Cao et al., 2018). This also

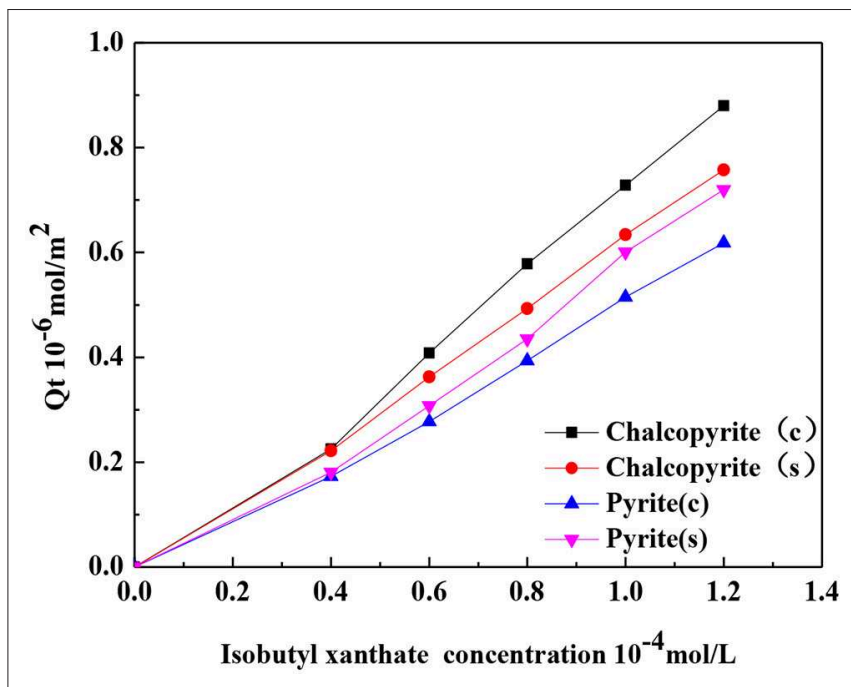

FIGURE 6 | Adsorption concentration at the surfaces of samples as a function of isobutyl xanthate concentration.

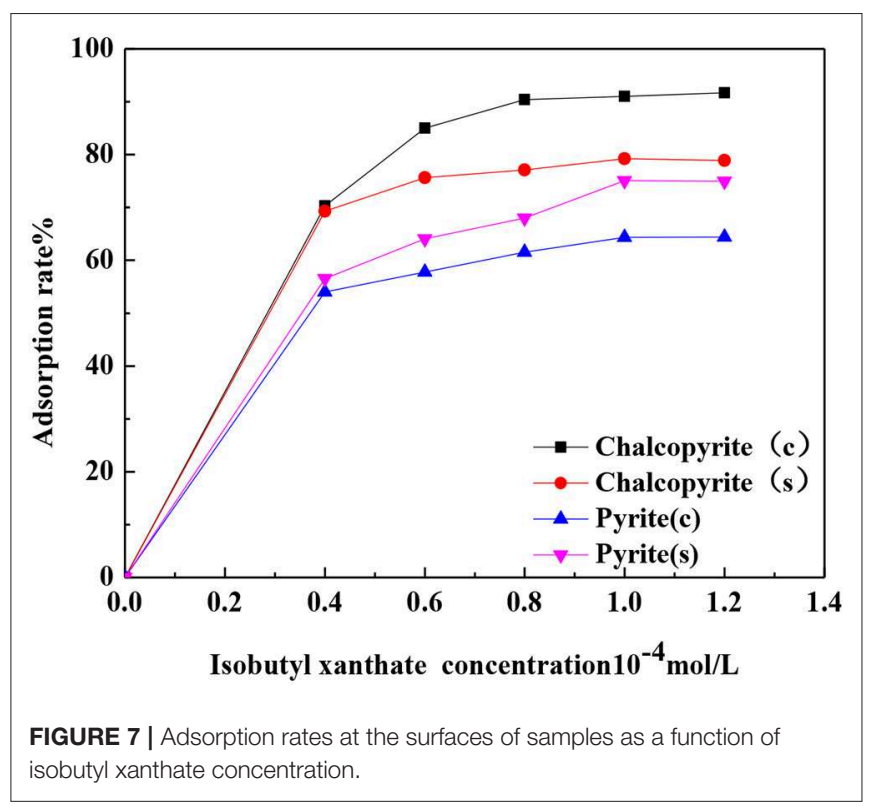

indicates that ceramic media grinding is beneficial to the flotation of chalcopyrite, which is consistent with the flotation results of the dosage isobutyl xanthate. Compared with pyrite ground with steel balls, grinding with nano-ceramic balls decreased the iron concentration at the surface of pyrite from 7.98 to $7.71 \%$ and the sulfur concentration from 21.5 to $20.58 \%$, whereas the oxygen concentration increased from 27.35 to $34.65 \%$. This also indicates that steel media grinding is beneficial to the flotation of pyrite, which is consistent with the flotation results of the dosage isobutyl xanthate.

Figures 8C,D show the high-resolution spectra of Fe of chalcopyrite and pyrite, respectively, whereas Table 4 presents the qualification of iron species based on Fe 2p XPS spectra. 

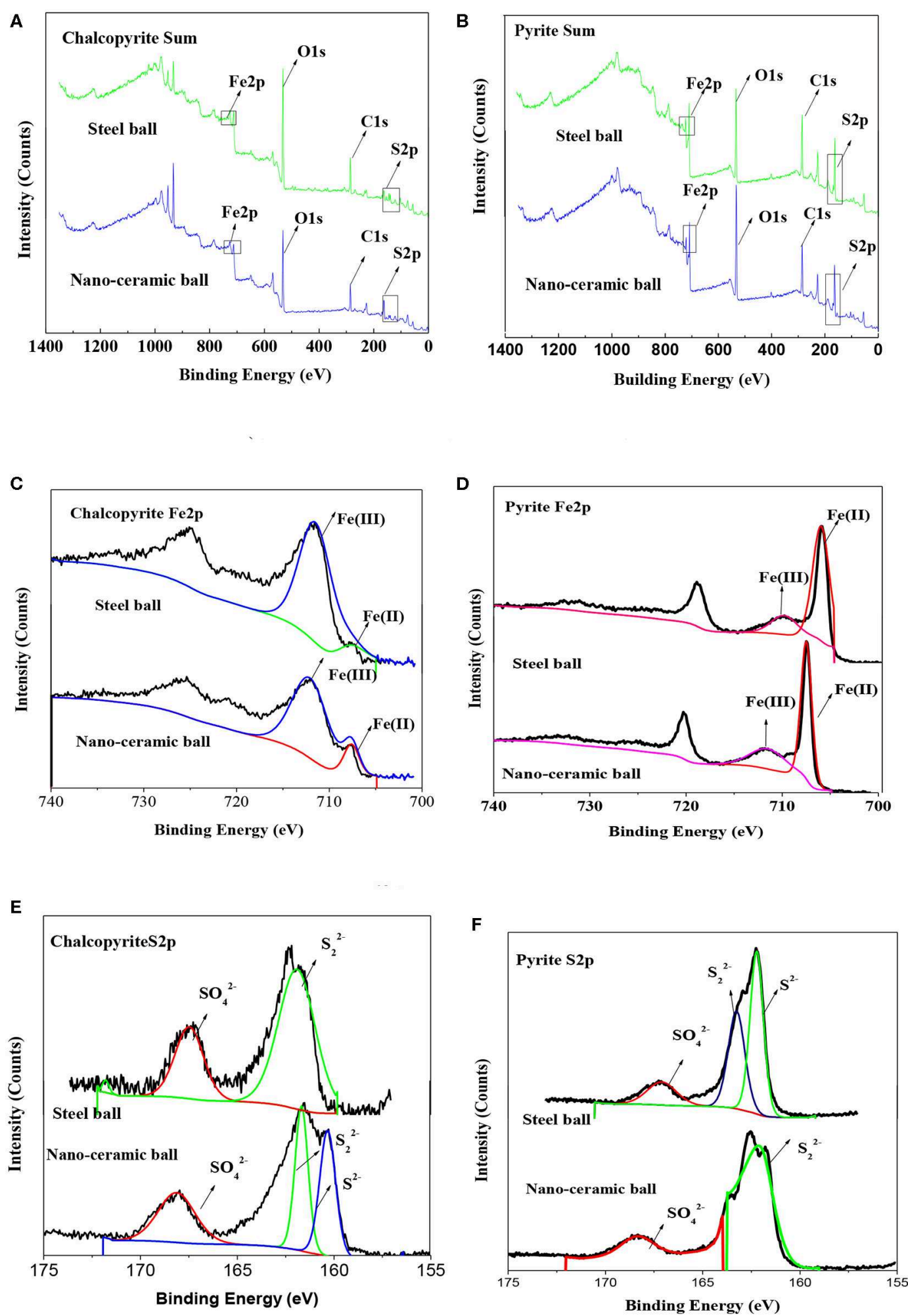

FIGURE 8 | XPS spectra of chalcopyrite and pyrite: (A) Chalcopyrite (survey); (B) Pyrite (survey); (C) Chalcopyrite (Fe 2p); (D) Pyrite (Fe 2p); (E) Chalcopyrite (S2p); (F) Pyrite (S2p).

In the $\mathrm{Fe} 2 \mathrm{p} 3 / 2$ spectra, the peaks near $711 \mathrm{eV}$ for $\mathrm{Fe}(\mathrm{III})-\mathrm{O}$ and at $708 \mathrm{eV}$ for $\mathrm{Fe}(\mathrm{II})-\mathrm{S}$, the $\mathrm{Fe}(\mathrm{III})-\mathrm{O}$ concentration at the surface of chalcopyrite ground using ceramic balls decreased significantly from 90.96 to $86.01 \%$ (Taheri et al., 2014; Mikhlin et al., 2016; Peng et al., 2017; Rabieh et al., 2017; Cao et al., 2018). This indicates that ceramic ball grinding can reduce the 
adsorption of iron oxide on the surface of chalcopyrite and is conducive to the flotation of chalcopyrite. Cao et al. (2018) found that pyrite has a higher energy site at approximately $707.2 \mathrm{eV}$; thus, $\mathrm{Fe}(\mathrm{II})-\mathrm{S}$ has the highest concentration in the pyrite $\mathrm{Fe}$ $2 \mathrm{p}$ spectra. The Fe(II)-S concentration at the surface of pyrite

TABLE 3 | Atomic concentration of elements in XPS at the surfaces of samples.

\begin{tabular}{llcccc}
\hline Mineral & Grinding media & \multicolumn{4}{c}{ Atomic concentration of element (\%) } \\
\cline { 3 - 6 } & & Fe & C & O & S \\
\hline Chalcopyrite & Ceramic & 10.63 & 33.28 & 39.71 & 16.38 \\
Chalcopyrite & Steel & 11.02 & 31.99 & 48.8 & 8.19 \\
Pyrite & Ceramic & 7.71 & 37.06 & 34.65 & 20.58 \\
Pyrite & Steel & 7.98 & 43.17 & 27.35 & 21.5
\end{tabular}

ground using ceramic balls significantly increased from 68.36 to 79.83\%. Rabieh et al. (2017) also found the same regular pattern in pyrite.

Figures 8E,F show the high-resolution spectra of $S$ of chalcopyrite and pyrite, respectively, whereas Table 5 presents the qualification of sulfur species based on the S 2p XPS spectra. Disulfide $\mathrm{S}_{2}^{2-}$ is produced at a binding energy range of 162.4$162.7 \mathrm{eV}$ and $\mathrm{S}^{2-}$ is produced at a lower binding energy range of $161.3-162.1 \mathrm{eV}$, whereas $\mathrm{SO}_{4}^{2-}$ is produced at higher binding energies of approximately $168 \mathrm{eV}$ (Peng et al., 2003a; Moslemi and Gharabaghi, 2017; Cao et al., 2018). Peng et al. (2003a) found that a 30 wt.\% chromium medium produced more sulfate at the surface of chalcopyrite than a mild steel medium. Figure $\mathbf{8 E}$ shows that ceramic balls produced more $S_{2}^{2-}$ at the surface of chalcopyrite than steel balls. Rabieh et al. (2017) found that there are more $\mathrm{SO}_{4}^{2-}$ at the surface of pyrite using ceramic media grinding compared with using steel media. In this paper, we also

TABLE 4 | Quantification of iron species at the surface of samples based on Fe 2p XPS spectra.

\begin{tabular}{|c|c|c|c|c|c|c|c|c|}
\hline \multirow{3}{*}{$\begin{array}{l}\text { Mineral } \\
\text { Grinding Media } \\
\text { Species }\end{array}$} & \multicolumn{2}{|c|}{ Chalcopyrite } & \multicolumn{2}{|c|}{ Chalcopyrite } & \multicolumn{2}{|c|}{ Pyrite } & \multicolumn{2}{|c|}{ Pyrite } \\
\hline & \multicolumn{2}{|c|}{ Ceramic } & \multicolumn{2}{|c|}{ Steel } & \multicolumn{2}{|c|}{ Ceramic } & \multicolumn{2}{|c|}{ Steel } \\
\hline & B.E. & at. $\%$ & B.E. & at. $\%$ & B.E. & at. $\%$ & B.E. & at. $\%$ \\
\hline $\mathrm{Fe}(\mathrm{II})$ & 707.58 & 13.99 & 707.52 & 9.04 & 707.48 & 68.36 & 706.28 & 79.83 \\
\hline $\mathrm{Fe}(\mathrm{III})$ & 712.08 & 86.01 & 711.48 & 90.96 & 711.48 & 31.64 & 710.08 & 20.17 \\
\hline
\end{tabular}

TABLE 5 | Quantification of sulfur species at the surface of samples based on S 2p XPS spectra.

\begin{tabular}{|c|c|c|c|c|c|c|c|c|}
\hline \multirow{3}{*}{$\begin{array}{l}\text { Mineral } \\
\text { Grinding Media } \\
\text { Species }\end{array}$} & \multicolumn{2}{|c|}{ Chalcopyrite } & \multicolumn{2}{|c|}{ Chalcopyrite } & \multicolumn{2}{|c|}{ Pyrite } & \multicolumn{2}{|c|}{ Pyrite } \\
\hline & \multicolumn{2}{|c|}{ Ceramic } & \multicolumn{2}{|c|}{ Steel } & \multicolumn{2}{|c|}{ Ceramic } & \multicolumn{2}{|c|}{ Steel } \\
\hline & B.E. & at. $\%$ & B.E. & at. $\%$ & B.E. & at. $\%$ & B.E. & at. $\%$ \\
\hline $\mathrm{S}^{2-}$ & 161.68 & 2.49 & 161.13 & 71.55 & 161.95 & 78.48 & 161.53 & 48.62 \\
\hline $\mathrm{S}_{2}^{2-}$ & 162.14 & 80.22 & - & - & - & - & 162.78 & 36.21 \\
\hline $\mathrm{SO}_{4}^{2-}$ & 168.78 & 17.29 & 168.08 & 28.45 & 168.36 & 21.52 & 167.83 & 15.18 \\
\hline
\end{tabular}
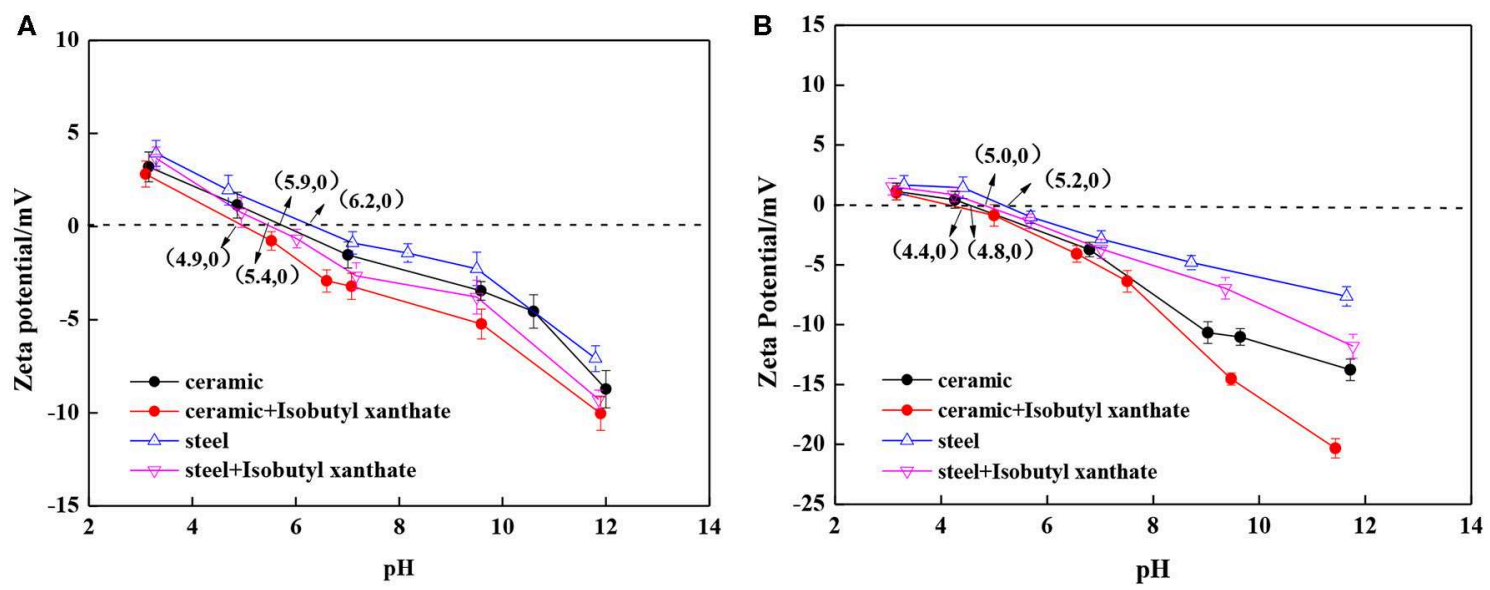

FIGURE 9 | Zeta potential of chalcopyrite and pyrite as a function of pH: (A) Chalcopyrite; (B) Pyrite. 
found the same regular pattern in pyrite, as presented in Table 5 and Figure 8F.

\section{Zeta Potential Measurement}

The surface potential of minerals will be affected by the adsorption of collectors, the degree of oxidation of minerals, the flotation atmosphere, and the influence of the grinding media (Peng and Grano, 2010a,b; Yin et al., 2018; Huang Z. et al., 2019; Jia et al., 2019). Figure 9 shows the zeta potential of chalcopyrite and pyrite as a function of $\mathrm{pH}$ in the absence and presence of $110^{-4} \mathrm{~mol} \mathrm{~L}^{-1}$ isobutyl xanthate using two different grinding media. Peng et al. (2003a) found that steel media tend to produce lower Eh values than a 30 wt.\% chromium medium when $\mathrm{Cu}^{2+}$ was added. Moreover, Peng and Grano (2010a,b) found that the zeta potential of pyrite is affected by the flotation atmosphere and the oxidation of sulfide minerals increased its isoelectric points. As shown in Figure 9A, the isoelectric point of chalcopyrite after nano-ceramic ball grinding is 5.9, whereas that of steel ball grinding is 6.2. The isoelectric point of chalcopyrite after nanoceramic ball grinding is consistent with that in the study by Huang X. et al. (2019). The increase in the isoelectric point of chalcopyrite after steel ball grinding is related to the hydroxide formed by the wear of the iron medium (Peng and Grano, $2010 a, b)$. After the addition of isobutyl xanthate, the isoelectric point of chalcopyrite shifted to the left because the negatively charged collector reduces the isoelectric point of chalcopyrite (Huang X. et al., 2019). As shown in Figure 9B, the isoelectric point of pyrite after nano-ceramic ball grinding is 4.8 , whereas that of the steel ball grinding is 5.2. This value is also similar to the values reported in previous studies (Yin et al., 2018; Huang X. et al., 2019). After the addition of isobutyl xanthate, the isoelectric point of pyrite shifted to the left. Iron media grinding can cause iron media pollution. Under alkaline conditions, a stable complex of xanthogen ions and iron hydroxides is adsorbed at the surface of pyrite (Yang et al., 2018; Yin et al., 2018). This is also consistent with the results shown in Figures 3, 6, 7.

\section{CONCLUSIONS}

Grinding media has significant influence on the flotation of chalcopyrite and pyrite. This effect is mainly related to the change in the surface properties of chalcopyrite and pyrite, which in turn affects their floatability. Grinding using steel medium easily produces oxidation species at the surface of chalcopyrite, thereby reducing its floatability. Scanning electron microscopy results show that the surface of the ground product

\section{REFERENCES}

Ahn, J. H., and Gebhardt, J. E. (1991). Effect of grinding mediachalcopyrite interaction on the self-induced flotation of chalcopyrite. Int. J. Miner. Process. 33, 243-262. doi: 10.1016/0301-7516(91) 90056-O

Bagci, E., Ekmekci, Z., and Bradshaw, D. (2007). Adsorption behaviour of xanthate and dithiophosphinate from their mixtures on chalcopyrite. Miner. Eng. 20, 1047-1053. doi: 10.1016/j.mineng.2007.04.011 and the flotation concentrate of chalcopyrite using nano-ceramic balls grinding is smooth, whereas the surface of the product ground using steel balls is rough and the surface of chalcopyrite flotation concentrates have many flocs. The flotation recovery of chalcopyrite after nano-ceramic ball grinding is higher than that of steel ball grinding. XPS demonstrated that steel ball grinding produced more iron hydroxide species than nanoceramic ball grinding, which is not conducive to the flotation of chalcopyrite. Adsorption experiments also show that nanoceramic media grinding contributes to the adsorption of isobutyl xanthate to chalcopyrite. The zeta potential of chalcopyrite indicates that ceramic media grinding is beneficial to the reduction of the isoelectric point of mineral flotation. However, steel media grinding is conducive to the flotation of pyrite. XPS was used to verify the flotation recovery of pyrite and the adsorption of isobutyl xanthate at the surface of pyrite. Further research should be conducted on the effect of nano-ceramic media on the selective separation of chalcopyrite from pyrite. Therefore, the nano-ceramic ball is a good grinding medium for chalcopyrite grinding, it is beneficial to improve the recovery rate of chalcopyrite. Steel balls is better for grinding pyrite than nano-ceramic balls. For copper-sulfur ore which is chalcopyrite associated pyrite, nano-ceramic balls can be used to replace steel balls as grinding media in some ways.

\section{DATA AVAILABILITY STATEMENT}

All datasets generated for this study are included in the article/supplementary material.

\section{AUTHOR CONTRIBUTIONS}

$\mathrm{CW}$ initiated the research topic. NL wrote the manuscript text. $\mathrm{BF}$ reviewed and edited the manuscript. JX, JW, YG, and NL performed experiments. All authors reviewed the manuscript.

\section{FUNDING}

This work was financially supported by the Projects of the National Natural Science Foundation of China (51764015) and (51964016).

\section{ACKNOWLEDGMENTS}

We acknowledge the support received from the Jiangxi Key Laboratory of Mining Engineering.

Beke, S., Korösi, L., Papp, S., Oszkó, A., and Nánai, L. (2009). XRD and XPS analysis of laser treated vanadium oxide thin films. Appl. Surf. Sci. 255, 9779-9782. doi: 10.1016/j.apsusc.2009.04.069

Bruckard, W., Sparrow, G., and Woodcock, J. (2011). A review of the effects of the grinding environment on the flotation of copper sulphides. Int. J. Miner. Process. 100, 1-13. doi: 10.1016/j.minpro.2011.04.001

Cao, Z., Chen, X., and Peng, Y. (2018). The role of sodium sulfide in the flotation of pyrite depressed in chalcopyrite flotation. Miner. Eng. 119, 93-98. doi: 10.1016/j.mineng.2018.01.029 
Corin, K. C., Song, Z. G., Wiese, J. G., and O’Connor, C. T. (2018). Effect of using different grinding media on the flotation of a base metal sulphide ore. Miner. Eng. 126, 24-27. doi: 10.1016/j.mineng.2018.06.019

Erdemoglu, M., and Sarikaya, M. (2002). The effect of grinding on pyrophyllite flotation. Miner. Eng. 15, 723-725. doi: 10.1016/S0892-6875(02) 00210-8

Feng, B., Peng, J., and Guo, W. (2019). The depression behavior and mechanism of carboxymethyl chitosan on calcite flotation. J. Mater. Res. Technol. 8, 1036-1040. doi: 10.1016/j.jmrt.2018.07.013

Feng, B., Zhong, C., Zhang, L., Guo, Y., Wang, T., and Huang, Z. (2020). Effect of surface oxidation on the depression of sphalerite by locust bean gum. Miner. Eng, 146:106142. doi: 10.1016/j.mineng.2019.106142

Forssberg, E., Sundberg, S., and Hongxin, Z. (1988). Influence of different grinding methods on floatability. Int. J. Miner. Process. 22, 183-192. doi: 10.1016/0301-7516(88)90063-4

Gonçalves, K. L. C., Andrade, V. L. L., and Peres, A. E. C. (2003). The effect of grinding conditions on the flotation of a sulphide copper ore. Miner. Eng. 16, 1213-1216. doi: 10.1016/j.mineng.2003. 05.006

Greet, C., Small, G., Steinier, P., and Grano, S. (2004). The magotteaux mill(R): investigating the effect of grinding media on pulp chemistry and flotation performance. Miner. Eng.17, 891-896. doi: 10.1016/j.mineng.2004. 03.003

Guo, W., Feng, B., and Peng, J. (2019). Depressant behavior of tragacanth gum and its role in the flotation separation of chalcopyrite from talc. J. Mater. Res. Technol. 8, 697-702. doi: 10.1016/j.jmrt.2018.05.015

Heyes, G. W., and Trahar, W. J. (1979). Oxidation-reduction effects in the flotation of chalcocite and cuprite. Int. J. Miner. Process. 6, 229-252. doi: 10.1016/0301-7516(79)90039-5

Huang, G., and Grano, S. (2006). Galvanic interaction between grinding media and arsenopyrite and its effect on flotation Part I. quantifying galvanic interaction during grinding. Int. J. Miner. Process. 78, 182-197. doi: 10.1016/j.minpro.2005.10.008

Huang, X., Huang, K., Jia, Y., Wang, S., Cao, Z., and Zhong, H. (2019). Investigating the selectivity of a xanthate derivative for the flotation separation of chalcopyrite from pyrite. Chem. Eng. Sci. 205, 220-229. doi: 10.1016/j.ces.2019.04.051

Huang, Z., Wang, J., Sun, W., Hu, Y., Cao, J., and Gao, Z. (2019). Selective flotation of chalcopyrite from pyrite using diphosphonic acid as collector. Miner. Eng, 140:105890. doi: 10.1016/j.mineng.2019. 105890

Jia, Y., Huang, K., Wang, S., Cao, Z., and Zhong, H. (2019). The selective flotation behavior and adsorption mechanism of thiohexanamide to chalcopyrite. Miner. Eng. 137, 187-199. doi: 10.1016/j.mineng.2019.04.015

Learmont, M. E., and Iwasaki, I. (1984). Effect of grinding media on galena flotation. Mining Met. Explor. 1, 136-143. doi: 10.1007/BF03402566

Li, C., and Gao, Z. (2017). Effect of grinding media on the surface property and flotation behavior of scheelite particles. Powder Technol. 322, 386-392. doi: 10.1016/j.powtec.2017.08.066

Li, C., and Gao, Z. (2018). Tune surface physicochemical property of fluorite particles by regulating the exposure degree of crystal surfaces. Miner. Eng. 128, 123-132. doi: 10.1016/j.mineng.2018.08.044

Liao, N., Wu, C., Wu, Z., and Wang, X. (2019). Effect of nano ceramic ball on grinding and flotation in copper sulfur ore. Nonferrous. Met. Eng. 9, 70-76. doi: 10.3969/j.issn.2095-1744.2019.01.012 (In Chinese).

Martin, C. J., McIvor, R. E., Finch, J. A., and Rao, S. R. (1991). Review of the effect of grinding media on flotation of sulphide minerals. Miner. Eng. 4, 121-132. doi: 10.1016/0892-6875(91)90028-T

Mikhlin, Y., Karacharov, A., Tomashevich, Y., and Shchukarev, A. (2016). Cryogenic XPS study of fast-frozen sulfide minerals: flotation-related adsorption of n -butyl xanthate and beyond. J. Electron Spectrosc. 206, 65-73. doi: 10.1016/j.elspec.2015.12.003

Moslemi, H., and Gharabaghi, M. (2017). A review on electrochemical behavior of pyrite in the froth flotation process. J. Ind. Eng. Chem. 47, 1-18. doi: 10.1016/j.jiec.2016.12.012

Nagaraj, D., and Brinen, J. (2001). SIMS study of adsorption of collectors on pyrite. Int. J. Miner. Process. 63, 45-57. doi: 10.1016/S0301-7516(01) 00043-6
Palm, N. A., Shackleton, N. J., Malysiak, V., and O'Connor, C. T. (2010). The effect of using different comminution procedures on the flotation of sphalerite. Miner. Eng. 23, 1053-1057. doi: 10.1016/j.mineng.2010.08.001

Palm, N. A., Shackleton, N. J., Malysiak, V., and O'Connor, C. T. (2011). The effect of using different comminution procedures on the flotation of platinum group. Miner. Eng. 24, 731-736. doi: 10.1016/j.mineng.2011.01.001

Peng, H., Wu, D., and Abdelmonem, M. (2017). Flotation performances and surface properties of chalcopyrite with xanthate collector added before and after grinding. Results Phys. 7, 3567-3573. doi: 10.1016/j.rinp.2017. 09.028

Peng, Y., and Grano, S. (2010a). Effect of grinding media on the activation of pyrite flotation. Miner. Eng. 23, 600-605. doi: 10.1016/j.mineng.2010. 02.003

Peng, Y., and Grano, S. (2010b). Effect of iron contamination from grinding media on the flotation of sulphide minerals of different particle size. Int. J. Miner. Process. 97, 1-6. doi: 10.1016/j.minpro.2010. 07.003

Peng, Y., Grano, S., Fornasiero, D., and Ralston, J. (2003a). Control of grinding conditions in the flotation of chalcopyrite and its separation from pyrite. Int. J. Miner. Process. 69, 87-100. doi: 10.1016/S0301-7516(02) 00119-9

Peng, Y., Grano, S., Fornasiero, D., and Ralston, J. (2003b). Control of grinding conditions in the flotation of galena and its separation from pyrite. Int. J. Miner. Process. 70, 67-82. doi: 10.1016/S0301-7516(02) 00153-9

Qu, X., Xiao, J., Liu, G., Liu, S., and Zhang, Z. (2016). Investigation on the flotation behavior and adsorption mechanism of 3-hexyl-4amino-1,2,4-triazole-5-thione to chalcopyrite. Miner. Eng. 89, 10-17. doi: 10.1016/j.mineng.2015.12.015

Rabieh, A., Albijanic, B., and Eksteen, J. J. (2017). Influence of grinding media and water quality on flotation performance of gold bearing pyrite. Miner. Eng. 112, 68-76. doi: 10.1016/j.mineng.2017.07.010

Rao, M. Y., and Natarajan, K. A. (1988). Influence of galvanic interaction between chalcopyrite and some metallic materials on flotation. Miner. Eng. 1, 281-294. doi: 10.1016/0892-6875(88)90018-0

Rao, S. R., Moon, K. S., and Leja, J. (1976). "Effect of grinding media on the surface reactions and flotation of heavy metal sulphides," in, A. M. Flotation, Gaudin Memorial. Flotation: A.M. Gaudin Memorial Vol I (New York, NY: Fuerstenau, MD, Ed., A.I.M.E), 1, 509

Shi, G. M., and Zhou, Y. C. (2019). The impact of SAG pebbles as media vs steel media on flotation performance of a copper sulphide ore. Can. Metall. Quart. 58, 362-366. doi: 10.1080/00084433.2019.1590038

Taheri, B., Abdollahy, M., Tonkaboni, S. Z. S., Javadian, S., and Yarahmadi, M. (2014). Dual effects of sodium sulfide on the flotation behavior of chalcopyrite: I. effect of pulp potential. Int. J. Miner. Met. Mater. 21, 415-422. doi: 10.1007/s12613-014-0924-7

Van Deventer, J. S. J., Ross, V. E., and Dunne, R. C. (1991). "The effect of milling environment on the selective flotation of chalcopyrite from a complex sulphide ore," in Proceeding XVII International Mineral Proceeding Congress Dresden, 129-140.

Woods, R. (1976). Electrochemistry of Sulphide Flotation: Flotation. New York, NY: AIME

Wu, C., Lei, A., Jiang, L., Yuan, C., Yin, Q., and Shen, T. (2019). Semi-autogenous grinding mill pebbles as a vertically stirred mill medium. Sep. Sci. Technol. 1-10. doi: 10.1080/01496395.2019.1675697

Yang, X., Albijanic, B., Liu, G., and Zhou, Y. (2018). Structure-activity relationship of xanthates with different hydrophobic groups in the flotation of pyrite. Miner. Eng. 125, 155-164. doi: 10.1016/j.mineng.2018.05.032

Yao, W., Li, M., Zhang, M., Cui, R., Jiang, H., Li, Y., et al. (2019). Effects of grinding media on flotation performance of calcite. Miner. Eng. 132, 92-94. doi: 10.1016/j.mineng.2018.12.005

Yekeler, M., Ulusoy, U., and Hiçyilmaz, C. (2004). Effect of particle shape and roughness of talc mineral ground by different mills on the wettability and floatability. Powder Technol. 140, 68-78. doi: 10.1016/j.powtec.2003. 12.012

Yin, W., Xue, J., Li, D., Sun, Q., Yao, J., and Huang, S. (2018). Flotation of heavily oxidized pyrite in the presence of fine digenite particles. Miner. Eng. 115, 142-149. doi: 10.1016/j.mineng.2017.10.016 
Yuan, X.-M., Pålsson, B., and Forssberg, K. S. (1996). Flotation of a complex sulphide ore II. influence of grinding environments on sulphide selectivity and pulp chemistry. Int. J. Miner. Process. 46, 181-204. doi: 10.1016/0301-7516(95) 00095-X

Zhang, X., Han, Y., Gao, P., Li, Y., and Sun, Y. (2019). Effects of particle size and ferric hydroxo complex produced by different grinding media on the flotation kinetics of pyrite. Powder Technol. 360, 1028-1036. doi: 10.1016/j.powtec.2019.11.014

Zhang, Z., Dong, L., and Wang, Z. (2013). A Super Wear-Resistant AluminaCeramic Ball and Its Preparation Method. CHN, patent, ZL201310174278.6, 2013-08-07. (In Chinese)
Conflict of Interest: The authors declare that the research was conducted in the absence of any commercial or financial relationships that could be construed as a potential conflict of interest.

Copyright (c) 2020 Liao, Wu, Xu, Feng, Wu and Gong. This is an open-access article distributed under the terms of the Creative Commons Attribution License (CC BY). The use, distribution or reproduction in other forums is permitted, provided the original author(s) and the copyright owner(s) are credited and that the original publication in this journal is cited, in accordance with accepted academic practice. No use, distribution or reproduction is permitted which does not comply with these terms. 